\title{
Georgian stem formants and nominalization
}

Gallagher Flinn

\begin{abstract}
The Georgian verb system is complex, and in many cases the function and meaning of certain morphemes is not entirely clear. One such morpheme, the stem formant, appears in both non-perfect verbs and nominal structures. Although they are usually associated with aspect in the verb, I propose that there are several advantages to treating stem formants as nominal heads bearing the feature [+collective]. If stem formants are nominalizers, then several facts about their distribution can be explained, including their historical origin, their presence in abstract and verbal nouns, and their absence from verbs which assign ergative case to their subjects. Doing so also makes it possible to bring Georgian split ergativity closer in line with other analyses of ergative splits in Basque (Laka, 2006) and Chol (Coon, 2013).
\end{abstract}

Keywords: syntax, Georgian, nominalization, split ergativity, stem formant, thematic suffix

1. Introduction. Georgian verb structure is complex, and much of its morphology is still subject to active debate. One example is the stem formant (also called the thematic suffix), a morpheme whose purpose and meaning, while traditionally associated with aspect, still lack consensus. Environments in which stem formants appear are diverse. Nearly all finite verbs take stem formants, as do non-finite verbal nouns (masdars) and participles, but they are also restricted in that they never co-occur with verb screeves ${ }^{1}$ that assign ergative case to their subjects, and it is a safe hypothesis that stem formants are the locus of split ergativity in Georgian. Unlike many other facts about Georgian verbs, the generalization that verbs only assign ergative case if they do not contain a stem formant has absolutely no exceptions ${ }^{2}$.

Characterizing the stem formant itself, however, is difficult. Although it appears to interfere with ergative case, there is no evidence that it assigns case itself. Stem formants also appear to be related to aspect - both of the ergative case assigning screeves, the aorist and the optative, are non-perfective. However, stem formants are also necessary in forms like participles, verbal nouns, and abstract nouns, where no aspect is specified or expected.

In this paper I argue that the diverse environments in which the stem formant appears can be explained if the stem formant is actually a nominalizing suffix. This is a useful characterization of the stem formant in that it explains why the stem formant can appear in such a variety of verbal environments without contributing straightforwardly aspectual meaning. At the same time, it unifies stem formants in nominals and verbs, obviating the need to assume that these morphemes, though otherwise identical, have different meanings. Furthermore, the presence of nominal structure inside the verb itself brings Georgian in line with recent work on split ergativity in which the split is

\footnotetext{
${ }^{1}$ Masdars are the name traditionally given to the nominalized forms of verbs in Georgian. Screeves (from mckrivi 'row') are verb conjugations corresponding to combinations of tense, aspect and mood that often do not have a oneto-one correlate in English grammar - for example, the aorist screeve refers to completed actions undertaken by the subject deliberately in the past, while the perfect screeve is used both in the traditional sense of the English perfect, but also to mark evidentiality in the past tense and under negation instead of the aorist. Because of the potential for misleading terminology, I will use the conventional term screeve to refer to individual TAM forms in the Georgian verb paradigm.

${ }^{2}$ Of course there is one exception. Causativized verbs may contain a stem formant and still assign ergative case, provided that the stem formant appears between the root and the causativizing morpheme. This will be addressed later in the paper.
} 
determined by the presence of a nominal domain which bifurcates the clause (Laka, 2006; Coon, 2013).

Section 2 describes the distribution of stem formants in Georgian and gives some background on its status in the verb. Section 3 examines recent analyses which tie the stem formant to aspect or something like it. Section 3 argues that, while an aspectual analysis is not necessarily incompatible with the data, treating the the stem formant as a nominalizing head captures more insights about the stem formant's distribution that make it potentially incompatible with an analysis that treats it as a functional head related to aspect. Finally, Section 4 briefly discusses split ergativity analyses for Basque and Chol that potentially fits well with a nominalization analysis, as well as some outstanding problems.

2. Distribution. Stem formants are a set of suffixes in the Georgian verb which are traditionally treated as tense or aspect markers, but their precise meaning has not been settled. They have been associated with a past/non-past distinction (Aronson, 1990), imperfective aspect (Cherchi, 1996), or more generally a dummy element which carries no meaning of its own but is used to distinguish particular screeves from one another (Hewitt, 1995; Lomashvili and Harley, 2011). Most recently, McGinnis (2016) proposes that the stem formant carries the feature [ \pm bounded], a feature which is distinct from but compatible with [ \pm perfect], while Nash (2017) proposes that the stem formant is a special type of eventive predicate which takes $v \mathrm{P}$ as its complement and hosts the subject DP in its specifier.

Stem formants $\{e b, e v, o b, a m, a v\}$ follow the root in many Georgian verb forms. All verb roots are lexically specified for a particular stem formant in their transitive form, but the most common of which is $e b$, which also serves as a default form when the stem formant does not appear directly adjacent to the root, as in passives and causatives. (1) shows examples of each stem formant in the present screeve. In each case, the form of the stem formant is conditioned by the verb root.

(1) Stem Formant Types ${ }^{3}$
a. $e b$
d. $a m$
a-oxr-eb-s
i-rt'q-am-s
VER-hit-SF-3sg.pres
' $\mathrm{X}$ is hitting itself.'
VER-waste-SF-3sg.pres
' $\mathrm{X}$ is wasting $\mathrm{Y}$ '
b. $e v$
e. $a v$
a-l-ev-s
VER-use.up-SF-3sg.pres
u-pkv-av-s
' $\mathrm{X}$ is milling something (wheat) for someone.'
VER-mill-SF-3sg.pres
' $\mathrm{X}$ is using up $\mathrm{Y}$ '
c. $o b$
i-cxovr-ob-s
VER-live-SF-3sg.pres
' $\mathrm{X}$ is living.'

Each verb also has a corresponding non-finite masdar form, which behaves in all other respects like a noun. Masdars are made up of an optional preverb which usually marks telicity, the verb

\footnotetext{
${ }^{3} \mathrm{PV}=$ preverb, $\mathrm{VER}=$ version vowel, $\mathrm{SF}=$ stem formant
} 
root, a stem formant, and a case marker. Not all verbs have stem formants, but verbs without stem formants in the present screeve also invariably lack them in their masdar as well. Moreover, the form of the stem formant in the masdar is always the same for present screeve transitives.
a. c'er-s
write-3sg.pres
' $\mathrm{X}$ is writing $\mathrm{Y}$ '
b. c'er-a
write-NOM
'writing'
a. a-dn-ob-s
VER-melt-SF-3sg.pres
'X melts Y
b. dn-ob-a
melt-SF-NOM
'melting'

Nearly all screeves require a stem formant, as do masdars and participles. The table in (4) includes most of the verbal forms in which a stem formant may appear. Critically, ergative case is barred for all arguments of the verbs below.

(4) Forms with Stem Formants

\begin{tabular}{l|rl} 
Screeve & Verb & Meaning \\
\hline \hline Present & a-šen-eb-s & X is building Y \\
Future & a-a-šen-eb-s & X will build Y \\
Imperfect & a-šen-eb-da & X was building Y \\
Conditional & a-a-šen-eb-da & If X would build/built Y \\
Present Subjunctive & a-šen-eb-des & If X were building Y \\
Future Subjunctive & a-a-šen-eb-des & If X could possibly build Y \\
Perfect & a-u-šen-eb-i-a & X apparently built Y \\
Past Subjunctive & a-e-šen-eb-in-a & X should have built Y \\
\hline \hline Masdar & a-šen-eb-a & (the act of) building \\
Active participle & m-šen-eb-eli & a builder \\
Perfect participle & a-šen-eb-ul-i & a built thing \\
Privative participle & a-u-šen-eb-eli & an unbuilt thing
\end{tabular}

Ergative case is only possible for subjects of transitive verbs in the aorist (5) and optative (6) screeves. This fact is what uncontroversially ties the stem formant to the phenomenon of split ergativity in Georgian. The aorist and optative screeves are also the only screeves that can assign ergative case.

(5) Aorist

nino-m saxl-i

Nino-ERG house-NOM

a-a-šen-a

PV-VER-build-3sg.aor

'Nino built a house.'
(6) Optative

$$
\begin{aligned}
& \text { nino-m saxl-i } \\
& \text { Nino.ERG house-NOM } \\
& \text { a-a-šen-o } \\
& \text { PV-VER-build-SF-3sg.opt } \\
& \text { 'Nino may build a house.' }
\end{aligned}
$$

The data above show the two major puzzles in analyzing the stem formant. First, it is too variably distributed to be straightforwardly tied to a familiar aspect or tense. At the same time 
it clearly defines the border between verbs that may assign ergative case and verbs that may not. Ideally the stem formant requires an analysis that can account for both its distribution and its status with respect to ergativity. The following section reviews two recent proposals for an analysis that uniformly describes the purpose of the stem formant.

3. Not quite aspect The variability problem requires that an analysis of the stem formant be at least divorced from grammatical perfective and imperfective aspect as they are conventionally understood, where perfective verbs describe some situation as a unified whole and imperfective verbs may pick out some internal temporal structure (Comrie, 1976). The range of environments in which the stem formant appears is too diverse. A second confounding factor is that the presence or absence of a preverb also appears to condition aspectual interpretation. In (7), aspect appears to be defined by the preverb $\check{s}$. The aorist, which is supposedly perfective, patterns with the imperfective in that it is unable to take the time adverbial 'in two hours.'

(7) (Nash, 2017)

a. Aorist With Preverb

nino-m magida še-yeb-a or saat-ši

nino-ERG table.NOM PV-paint-3sg.aor two hour-in

'Nino painted the table in two hours.'

b. Aorist Without Preverb

*nino-m magida yeb-a or saat-ši

nino-ERG table.NOM paint-3sg.aor two hour-in

Intended: 'Nino was engaging in painting the table in two hours'

c. Imperfective

*nino magida-s y-eb-av-da or saat-ši

nino.NOM table-DAT paint-SF-3sg.imp two hour-in

'Nino was painting the table in two hours'

In order to account for this incongruity, McGinnis (2016) proposes that stem formants bear a feature [ \pm bounded] that is related to but distinct from aspect. Verbs with [+bounded] denote events with some specified endpoint, while [-bounded] events do not. This makes the feature compatible with both perfective and imperfective aspects. The imperfective screeve carries the feature [+past, -bounded], the present is [-past, -bounded], and the future is [-past, +bounded] to account for the apparent perfectivity of verbs in the future screeve.

Aorist verbs are [+past, +bounded], a feature combination which is subject to contextual allomorphy. Stem formants are thus present in the aorist, but are realized as $\varnothing$. In this system, the stem formant is sensitive to ergative splits, but they are not the cause. Instead, they are subject to allomorphy in the same environments in which ergative case is assigned. In all verbs, roots, which are category-neutral (Marantz, 1997) are selected by a verbal head $v$, which is in turn selected by Aspect. A version vowel Voice, which determines transitivity, is added later. The trees below are adapted from McGinnis (2016). 
(8)

$a$-šen-eb-s

'X builds Y'

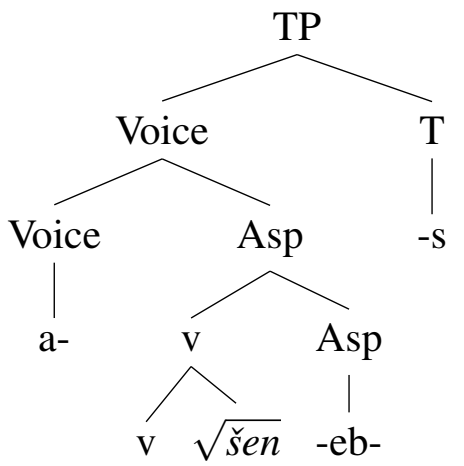

The selection of $v$ by Asp explains the appearance of stem formants in masdars. Because masdars lack a Voice head, the Asp head attaches directly to the verb and is followed by the nominalizer $-a$.

(9) ร̌en-eb-a

'building'

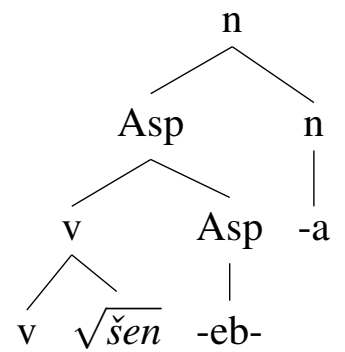

One advantage of this analysis is that it potentially answers a question about the relationship between the aorist screeve and the perfect screeve. Perfect screeve verbs are clearly [+past], but take dative subjects and usually contain a stem formant. They are also used in place of the aorist under negation.

(10) nino-m saxl-i ar a-a-šen-a nino-ERG house-NOM PV-VER-build-3sg.aor

'Nino built the house (deliberately)'

(11) nino-s saxl-i ar a-u-šen-eb-i-a nino-DAT house-NOM PV-VER-build-SF-INV-3sg.aux

'Nino didn't build the house (possibly deliberately, but unspecified)'

The difference between (10) and (11) is usually considered to be tied to volitionality, and according to speakers, the negated aorist has more of a categorical sense to it. In (10), Nino did not build the house because she did not want to, nor does she intend to in the future. In (11), the reasons for why Nino did not build the house are unknown, and there is still the possibility that Nino might build the house in the future (Boeder, 2000). This is not :w compatible with a [-bounded] interpretation for the verb, but further investigation is required. 
However, it should also be noted that stem formants on masdar are mandatory. This is potential sticking point in that it demands that a nominalizing suffix attach to [-bounded] aspect. If a masdar's root is specified for a stem formant, then it must appear with that stem formant. [-bounded] may very well be an appropriate feature for verbal nouns, but if the conditions for the stem formant's $\emptyset$-allomorphy is [+past, +bounded], then masdars, which have no tense, will never induce the alternation anyway. This means that the stem formant on the masdar is ambiguous between [+bounded] or [-bounded], raising the question of why it would be necessary on masdars in the first place if it conveys no information.

The height of the stem formant, however, is potentially problematic for this analysis. Because masdars do not contain a Voice head, they require that the stem formant attach at the $v \mathrm{P}$ level. Nonetheless, there is some evidence that the stem formant attaches above Voice in that stem formants do not always appear directly adjacent to the root. If the order of morphemes reflects a verb's internal structure (Baker, 1985) then intervening morphology is a possible diagnostic for the height of the stem formant. If that intervening material can be shown to be Voice, then there is reason to believe that there are multiple positions at which the stem formant can attach.

(Nash, 2017) argues that the transitive/passive alternation is evidence for the stem formant appearing outside of Voice. Transitive verbs passivize either by the addition of the reflexivizing version vowel $i$, or the addition of the detransitivizing suffix $-d$-, which surfaces between the root and the preverb. (12) shows the passive alternation for two verbs paint and rot. Here the passive removes the allomorphy specific to the root, replacing it with $-e b$.

(Nash, 2017)

a. vano xe-s yeb-av-s/tetr-eb-s

vano-NOM tree-DAT paint-SF-3sg.pres/white-SF-3sg.pres

'Vano is painting/whitening the tree.'

b. xe i-yeb-eb-a/tetr-d-eb-a

tree.NOM VER-paint-SF-3sg.pres/white-INTRANS-SF-3sg.pres

'The tree is being painted/whitened.'

(12) can be taken as potential evidence that stem formants can attach above Voice, meaning that there are at least two possible positions for them; one whose form is lexically conditioned by the root and one that is not. Nash (2017) argues that these facts can be obtained under the assumption that the stem formant actually is an expression of the imperfective, but that the aorist series, lacking stem formants, is structurally impoverished with respect to aspect. The aorist screeve is not perfective, but instead is aspectually neutral in that it refers to situations which include a starting point, and at least one stage, but no other information. The structure has an internal time, but no reference is made to the end of the eventuality. Instead, the preverb in the aorist screeve contributes telicity, defining an endpoint to the action.

(13) (Nash, 2017)

a. Imperfective

vano yeb-av-d-a magida-s

vano.NOM paint-SF-3sg.imp table-DAT

'Vano was painting the table.'

b. Aorist (with Preverb) 

vano-m še-yeb-a magida
vano-ERG PV-paint-3sg.aor table.NOM
'Vano painted the table (and finished)'
c. Aorist (no Preverb)
vano-m yeb-a magida
vano-ERG paint-3sg.aor table.NOM
'Vano painted the table' (=was engaged in painting the table but may or may not have finished)

These preverb-less aorist series verbs pattern with imperfectives in that, unlike aorist verbs with preverbs, they may not take completive time adverbials like 'in two hours', but do not have the same entailments as imperfectives when used with durative adverbials. In (14), the verb is in the aorist screeve and lacks a preverb, but is distinct from a true imperfective in that it entails the fact that Nino did not paint after 4.

(14) Aorist (no Preverb)

$$
\begin{aligned}
& \text { nino-m yeb-a magida sami-dan otx-amde } \\
& \text { nino-ERG paint-3sg.aor table three-from four-to } \\
& \text { 'Nino painted the table from } 3 \text { to } 4 \text { (and not after } 4 \text { ) }
\end{aligned}
$$

Taken together, (Nash, 2017) and (McGinnis, 2016) suggest that there are at least two points where the stem formant may enter the derivation for a verb; one which is close enough to the root to be sensitive to allomorphy, and one higher in the structure which may be outside of Voice. This predicts that it is possible for two stem formants to co-occur in the same verb, a prediction which is borne out in causatives:

(15) Causative (Lomashvili and Harley, 2011)

a-šen-eb-in-eb-s

VER-build-SF-CAUS-SF-3sg.pres

'X makes Y build Z'

One way of forming causative in Georgian is by adding the causativizing suffix in to a root and stem formant. Once added, the structure is treated as though it were a verb root, and may take another stem formant. This means that causatives are the one verb form which may contain a stem formant, but still assign ergative case. As long as the outer stem formant is absent, the aorist is possible.

Aorist Causative

a-a-šen-eb-in-a

PV-VER-build-SF-CAUS-3sg.aor

' $\mathrm{X}$ made $\mathrm{Y}$ build Z' 
These facts are incongruous with an aspectual interpretation for the stem formant, but not necessarily incompatible. For Nash (2017), the imperfective predicate theta-licenses its highest argument, the subject of a transitive verb, and the presence of two stem formants only signals that two arguments, the causer and the causee must be licensed. It is less clear why the causativizer must attach to a stem formant in the aorist, although it is a reasonable stipulation. For McGinnis (2016), the stipulation is unnecessary because the stem formant is present in all verbs. The internal stem formant will always be overt because the combination [+past, +bounded] is never available inside the causative structure. For Nash (2017) the disadvantage is that at least two positions are required for Asp, one inside Voice (masdars), and one outside. Aspect, however, may be used to block ergative case assignment, or to define two separate case assignment domains. For McGinnis (2016) the disadvantage is that the connection between split ergativity and the stem formant is incidental. The presence or absence of a stem formant has no bearing on ergativity; it is simply a morphological reflex of a set of features that happen to correspond to ergative case.

In the next section, I present an alternative account where stem formants are not aspectual, but are nominalizing heads that provide a structure that is compatible with non-perfect aspect. The presence of a nominalization corresponds to the ergativity split.

2. The stem formant as nominalizer: This section argues that the most general way to treat the stem formant is as a nominalizing suffix. This has two advantages; first, it allows for an explanation of all environments in which the stem formant appears, including participles and non-verbal nouns. There is also historical precedent for treating the stem formant as part of nominal morphology. Second, it ties the stem formant to extant analyses of split ergativity which posit that the reason for the split is a nominalizing element which creates a barrier which prevents the assignment of ergative case.

The most basic problem in tying the stem formant to aspect is their presence in unambiguous nominalizations like masdars and participles. Below in (18), the stem formant cannot be omitted from the participial form. It is difficult to see how a [-bounded] or an imperfective feature might apply to evictedness unless it is the state of being evicted which is unbounded.

(17) Future

$$
\begin{aligned}
& \text { a-barg-eb-s } \\
& \text { PV-evict-SF-3sg.fut } \\
& \text { 'X will evict Y' } \\
& \text { (18) Past participle } \\
& \text { a-barg-*(eb)-ul-i } \\
& \text { PV-evict-SF-PP-NOM } \\
& \text { 'evicted/an evicted thing' }
\end{aligned}
$$

It is also difficult to resolve the availability of a perfective reading in the future with the presence of the stem formant. If there is an aspectual meaning attached to its presence, then the assumption must be that it is [-past, +bounded]. However, the perfectivity of the future screeve bears no relationship to the presence of the stem formant. The future screeve is ambiguous with respect to perfectivity, and compatible with either perfective or imperfective readings. Because the 
stem formant is required in the futures screeve, there is no way to tie its presence directly to aspect in the future. Masdars, on the other hand, may distinguish aspect, but it is not done with the stem formant, but with the preverb (Tomelleri, 2006).

A second possibility is that what appear to be stem formants in masdars and participles are something else, and are merely a syncretism with the true stem formants that appear in verbs. This is, however, unlikely given that masdars and their corresponding verb forms invariably share the same form of the stem formant, shown earlier in (2).

Stem formant stacking in causatives also presents a challenge for an aspectual analysis in that they are not only possible in verbs, but also in masdars. A second stem formant is required in (19):

Causative stacking in masdars

a. gamo-kveqn-eb-a

PV-publish-SF-NOM

'publishing'

b. redakt'or-is mier c'eril-is gamo-kveqn-eb-in-eb-a

editor-GEN by letter-GEN PV-publish-SF-CAUSE-SF-NOM

'the editor's causing of the letter to be published'

Again, this is not entirely incompatible with an aspectual analysis, but it does raise the question of why any aspectual material would not only be doubled, but necessarily doubled within a nominalization. Why should aspect be marked twice?

If stem formants are nominalizers, however, nouns which countain stem formants become less problemantic. To begin with, there is good evidence that stem formants' diachronic origin is a nominal affix. Chafe (1970) points out that nouns in Old Georgian could be marked as either singular, plural, or collective, and that collective readings were differentiated by the addition of a suffix -eb-

(20) Plural

saxl-ta

house-NOM.PL

'the/some houses'
(21) Collective

saxl-eb-sa

house-COL-NOM

'houses in general'

In Proto-Georgian, the verb system distinguished between two categories of aspect, neither of which align completely with perfectivity or imperfectivity in English (Melikishvili, 2008). Linear or permansive aspect expressed an incomplete action of continuous duration, directly perceived by the viewer as occuring in the present and continuing into the future. This form was used to indicate both stativity and actions occurring at the time of utterance, but strictly present tense forms did not enter into Common-Georgian-Zan until until stem formants were added to the verb stem. During this period, collective nouns and durative aspect were marked with the same suffix (Harris, 1984). The second type of aspect in Proto-Georgian is described as punctual aspect. In the protolanguage, punctual verbs corresponded roughly to perspective aspect and suggested an action that had already been completed (aorist) or would be completed at a future time without any reference to internal temporal structure (optative). Harris (1984) also posits that it is entirely reasonable that the allomorphy of the stem formants is the result of relatively recent phonological changes. All 
stem formants in Georgian and its have the form Vowel-[+labial], immediately suggesting that they might have some common origin.

I therefore propose that structures with stem formants are nominalizations, and that they still bear the feature [+collective]. They may select any structure which is semantically compatible with collectivity and demarcate a domain in which ergative case (for whatever reason) cannot be assigned. This essentially reproduces the structure (8) and (9), the only difference being that no Aspect is necessary beneath Voice. I also follow Pylkkănen (2002) in treating $v$ as a functional head which introduces an argument. No Voice is present, but in transitive verbs, the stem formant selects a vP which does not take a subject. Instead, the subject must be introduced by a $v$ above the nominalization.

$$
\begin{aligned}
& a \text {-šen-eb-s } \\
& \text { 'X builds Y' }
\end{aligned}
$$

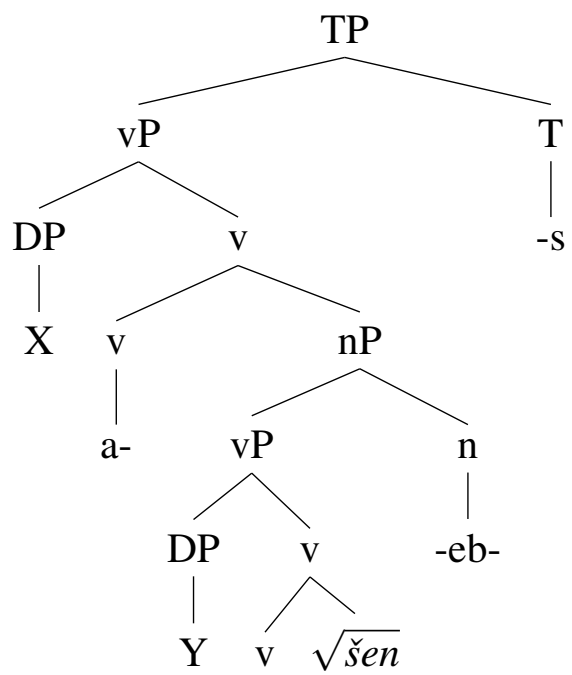

Treating the root as acategorial is not strictly necessary for the analysis. If stem formants are nominalizers then it does not matter a priori whether they are nominalizing a verb or a root. However, there is evidence from elsewhere in the language that roots may not come prepackaged with a category. Both nouns and adjectives can be used as verb roots easily enough, as shown in 23. The word k'amati 'debate' is clearly not a deverbal form or a masdar, as evidenced by the absence of a stem formant.

Noun to Verb
a. k'amat-i debate-NOM 'a debate'
b. i-k'amat-eb-s VER-debate-SF-3sg.fut ' $\mathrm{X}$ will debate $\mathrm{Y}$ '

\section{(24) Adjective to Verb}
a. gvian-i
late-NOM
'late'
b. da-i-gvian-eb-s
PV-VER-late-SF-3sg.fut
'X will be late'

In masdars, the minimal structure should be that the stem formant directly selects the root, but masdars may also optionally take a preverb, suggesting that some verbal structure is present. Following Nash (2017) I take this as a [+telic] feature and assume that it is associated with some 
verbal head below the stem formant. Here the case marker $a$ is a nominative case head $\mathrm{K}$. The optional preverb $(a)$ is distinct from the version vowel $a$ above - with a preverb and stem formant the verb is aašenebs.

(a)-šen-eb-a
'building'

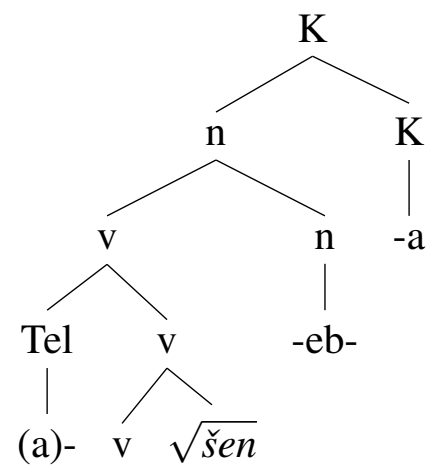

If stem formants are treated as nominalizers within verbs, then it should be expected that they are found elsewhere in nominal structures. This appears to be the case - adding a stem formant to an adjective appears to be one way in which nominalizations may be formed in Georgian. Stem formants may also turn human nominals into abstract nouns, shown below.

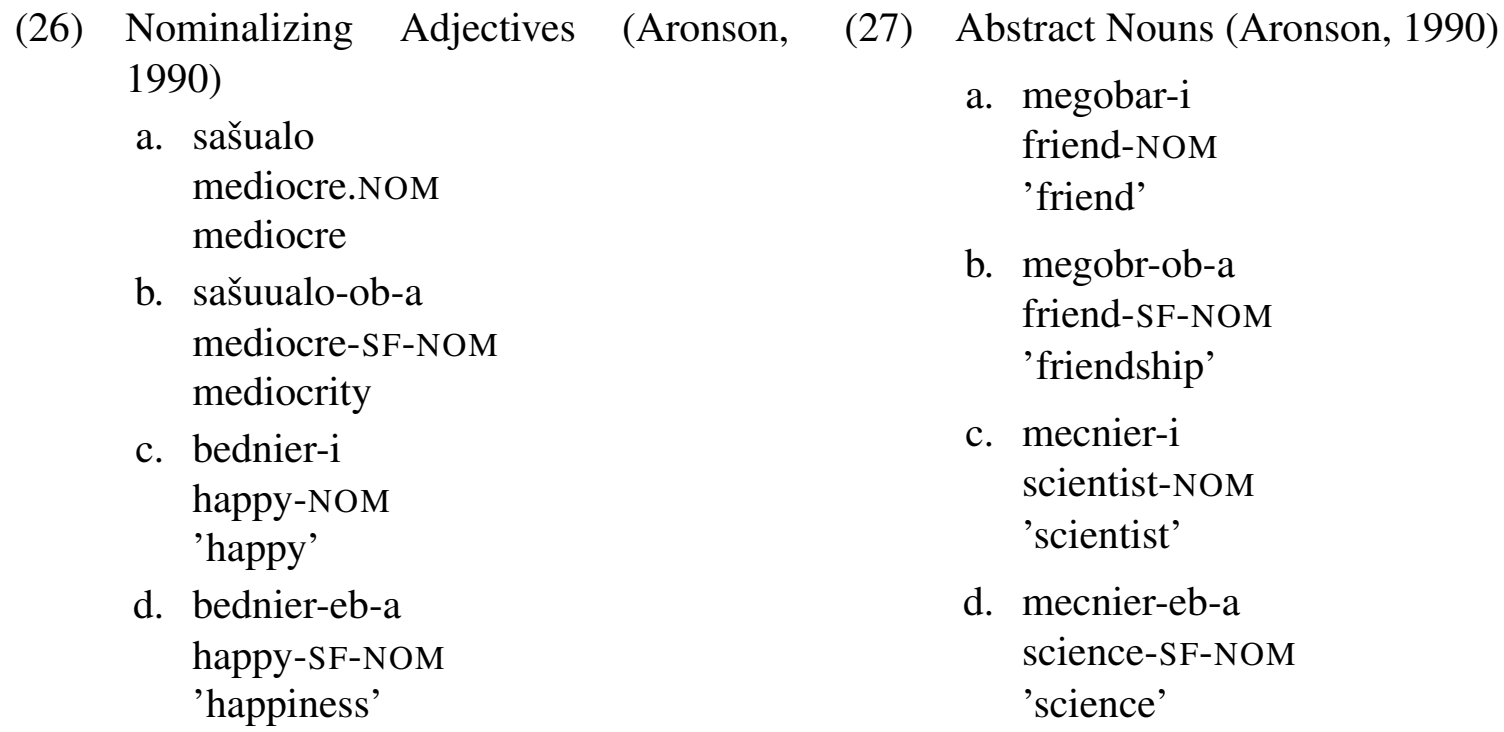

The data in (26) and (27) are not reconcilable with an analysis that ties the stem formant to aspect. Either the suffixes $-e b$ - and $-o b$ - above are not truly the same as stem formants, which is not implausible given that they are the only stem formant types with appear with nouns, or, less plausibly, the addition of Aspect may nominalize an adjective or create an abstract noun. However, if the stem formants in verbs are [+collective] nominalizers, the fact that stem formants are compatible with nouns and adjectives falls out naturally.

3. Stem formants and split ergativity One final argument for a nominalization analysis of stem formants is that it brings Georgian split ergativity in line with analyses of Basque (Laka, 2006) 
and Chol (Coon and Preminger, 2015), which treat split ergativity as the result of a biclausal structure created by a nominal domain below the subject. As with Georgian, non-perfect tenses and aspects require extra structure and do not assign ergative case to their subjects. This split based on the restriction that "in order to appear as a complement to a nonperfective aspect marker, a stem must be nominalized" (Coon and Preminger, 2015). Although much more work is necessary, this restriction is intuitively appropriate for the move from 'linear' and 'punctual' aspect in ProtoGeorgian, to the more diverse aspects available in Modern Georgian, as the addition of the feature [+collective] could allow an Aspect head to pick out sets of sub-events within the collection.

Georgian, however, presents two complications for this analysis. The first is that both Basque and Chol use auxiliary verbs in non-perfect contexts to introduce their subjects. Georgian, if it is actually not introducing its subject inside the nominalization, runs out of morphology fairly quickly for introducing a subject and there is certainly no overt auxiliary available.

The second problem is that, while it is tempting to write a rule that, like Chol, only intransitive verbs are nominalized, the status of the version vowel and Voice is still questionable. If the verbal root selected by the stem formant must be intransitive, then there is no obvious reason why detransitivizing morphology like $-d$ - would ever be necessary.

Much of the final analysis will rest on the position of $v$ and whether or not it is truly related to the version vowel. If the version vowel is transitive $v$, (it seems to be at least related to passive voice in some cases), then it does not intervene between the stem formant and the verb root as the passivizers $i$ - and - $d$ do because it does not induce the default stem formant - $e b-$. Why not? In nonergative environments, it is a potential candidate for the auxiliary which introduces the subject, but the fact that different positions might be required for passive $v$ and transitive $v$ is puzzling. Nonetheless, I believe that the advantages of treating the stem formant as a nominalizer outweight the outstanding problems.

4. Conclusion. In this paper I have argued that analyzing Georgian stem formants as nominalizers lacks some of the disadvantages associated with treating them as aspectual. A nominalization analysis treats all stem formants uniformly, both in and out of verbal structure, and has a solid diachronic basis for its development into verbal morphology. Further work, however, is necessary to determine where the stem formant attaches relative to Voice or transitive $v \mathrm{P}$.

\section{References}

Aronson, H. (1990). Georgian: A Reading Grammar. Slavica Publishers, Inc.

Baker, M. (1985). The mirror principle and morphosyntactic explanation. Linguistic Inquiry, 16(3):373-415.

Boeder, W. (2000). Evidentiality in georgian. In Empirical Approaches to Language Typology. Mouton de Gruyter.

Chafe, W. (1970). Meaning and the structure of language. Universit of Chicago Press.

Cherchi, M. (1996). A Study in Modern Georgian Morphosyntax: A Hierarchy-Based Analysis with Special Reference to 'Indirect Verbs' and 'Passives of State'. PhD thesis, University of Chicago.

Comrie, B. (1976). Aspect: An introduction to the study of verbal aspect and related problems. Cambridge University Press.

Coon, J. (2013). Aspects of Split Ergativity. Oxford University Press. 
Coon, J. and Preminger, O. (2015). Split ergativity is not about ergativity. Ms.

Harris, A. (1984). On the origin of series markers in kartvelian. Folia Slavica.

Hewitt, B. (1995). Georgian: A Structural Reference Grammar. John Benjamins.

Laka, I. (2006). Ergativity, chapter Deriving Split Ergativity in the Progressive. Springer.

Lomashvili, L. and Harley, H. (2011). Phases and templates in georgian agreement. Studia Linguistica, 65(3):233-267.

Marantz, A. (1997). No escape from syntax: Don't try morphological analysis in the privacy of your own lexicon. University of Pennsylvania Working Papers in Linguistics, 4(2).

McGinnis, M. (2016). The morphosyntax of thematic suffixes in georgian. The South Caucasian Chalk Circle.

Melikishvili, I. (2008). Georgian as an active/ergative split language. Bulletin of the Goergian National Academy of Sciences, 2(2).

Nash, L. (2017). The structural source of split ergativity and ergative case in georgian. In The Oxford Handbook of Ergativity. Oxford University Press.

Pylkkănen, L. (2002). Introducing Arguments. PhD thesis.

Tomelleri, V. S. (2006). The category of aspect in georgian, ossetic and russian. some areal and typological observations. In Atelier International Morphosyntaxe des langues du Caucase. 